\title{
STUDI LITERATUR : PERAN MASYARAKAT TERHADAP KONSERVASI HUTAN
}

\author{
Boby Rahman, Astri Pratiwi, Sania Fitri Sa'idah \\ Program Studi Perencanaan Wilayah dan Kota Fakutas Teknik Universitas Islam Sultan Agung \\ Email Korespondensi : sanfitrisaidah@gmail.com
}

\begin{abstract}
One of the efforts to conserve resources is to link local community wisdom to sustainable forest conservation. The study was conducted to figure out how local communities' prudence relates to the conservation of forest areas. Conservation is an effort to preserve or manage sustainable forests such as traditional customs that have the trust to protect forests. This is because people's role is vital to the management of forest areas. The study was done with a purpose (1) to find out how local prudence relates to the conservation of forest areas, (2) to see how people are involved in forest conservation, (3) to see what the cultural condition of local communities is. It is to hope that the areas of the forest will be preserved and that the awareness of communities in the importance of keeping properly.
\end{abstract}

Keywords: Culture, Forest Conservation, Community Role

\begin{abstract}
Abstrak
Salah satu upaya konservasi sumber daya adalah dengan mengkaitkan kearifan lokal masyarakat dalam pelestarian hutan yang berkelanjutan. Penelitian ini dilakukan dengan tujuan untuk mengetahui bagaimana kaitan antara kearifan lokal masyarakat terhadap konservasi kawasan hutan. Konservasi merupakan suatu upaya pelestarian atau pengelolaan suatu wilayah yang berkelanjutan. Salah satu upaya dari konservasi hutan adalah dengan mengkaitkan kearifan lokal masyarakat dalam pelestarian hutan yang berkelanjutan seperti adat istiadat yang memiliki kepercayaan untuk melindungi hutan. Hal ini dikarenakan peran masyarakat sangatlah penting dalam pengelolaan kawasan hutan. Penelitian ini dilakukan dengan tujuan (1) untuk mengetahui bagaimana kaitan antara kearifan lokal terhadap konservasi kawasan hutan, (2) mengetahui bagaimana peran masyarakat terhadap konservasi hutan, (3) untuk mengetahui bagaimana kondisi kebudayaan masyarakat lokal. Adanya upaya-upaya tersebut dapat diharapkan kawasan hutan akan terjaga kelestariannya dan adanya kesadaran dalam masyarakat akan pentingnya menjaga hutan dengan baik.
\end{abstract}

Kata Kunci: Kebudayaan, Konservasi Hutan, Peran Masyarakat 


\section{PENDAHULUAN}

Indonesia merupakan negara yang terkenal dengan seribu pulau serta memiliki jenis hutan yang berbeda namun, satu kesatuan karena memiliki iklim yang sama di berbagai pulau. Jenis hutan di Indonesia sangat beragam, setiap pulau besar di Indonesia memiliki hutan yang sangat beragam juga. Diantaranya hutan yang berada di Indonesia adalah hutan lindung, hutan tropis, hutan konservasi, hutan suaka alam, hutan produksi, hutan homogen dan hutan hetrogen (Nabilla et al., 2017). Tidak dapat dipungkiri bahwa Indonesia memang dikenal sebagai negara dengan sumber daya alam yang melimpah dan juga memiliki keindahan alam yang menjadi daya tarik tersendiri.

Menyandang predikat sebagai negara tropis, memang tidak dapat diragukan lagi bahwa Indonesia memiliki banyak hutan tropis yang tersebar di berbagai pulau di seluruh Indonesia, seperti Pulau Kalimantan, Pulau Sumatera, Pulau Jawa, dan pulau-pulau lainnya. Hal inilah yang membuat Indonesia dapat dikatakan sebagai paru-paru dunia, terlebih Pulau Kalimantan yang memang diberikan predikat sebagai pengekspor oksigen terbesar di dunia.

Tidak hanya sebagai sumber oksigen, hutan juga dimanfaatkan sebagai penghasil sumber daya alam dan juga sebagai tempat tinggal makhluk hidup seperti tumbuhan dan hewan. Selain sebagai view keindahan, hutan juga berperan penting dalam kehidupan makhluk hidup disekitarnya dan juga memberikan banyak manfaat terhadap lingkungan disekitarnya.

Dengan kekayaan alam yang melimpah, membuat para oknum yang tidak bertanggung jawab mulai serakah akan namanya pemenuhan kebutuhan untuk kepentingan pribadi. Seiring berjalannya waktu, tentunya mulai bermunculan masalah-masalah yang berkaitan dengan hutan sendiri. Indonesia sendiri tidak luput dari permasalahan hutan ini. Mulai dari masalah pengelolaan, pemanfaatan hingga peralihan fungsi lahan yang terjadi di berbagai daerah dan menimbulkan kerusakan alam serta penurunan kualitas pada sumberdaya hutan itu sendiri (Rosmaladewi, Danuwikarsa, \& Panggabean, 2019). Selain itu, masalah yang bermunculan ini juga dapat berakibat terhadap penurunan keberadaan keberagaman ekosistem yang terdapat di hutan tersebut.

Hal ini dapat terjadi karena minimnya pengetahuan dan pengawasan pemerintah serta masyarakat terhadap pegelolaan serta pengembangan kawasan hutan dan juga kurangnya kebijakan pemerintah dalam pengelolaan kawasan hutan, terlebih kawasan hutan lindung 
(Gerihano, \& Simanjuntak, 2016) Perusakan lahan hutan sendiri juga dapat menyebabkan keberadaan makhluk hidup terancam punah (Utami \& Baskoro, 2017)

Untuk menanggulangi masalah tersebut, tentunya memakan waktu yang tidak singkat. Apalagi untuk penghijauan kembali yang mana membutuhkan modal yang cukup besar untuk ini. Namun, masyarakat sekitar dan juga pemerintah telah berusaha melakukan berbagai upaya untuk pelestarian hutan. Mulai dari penanggulangan secara modern serta secara budaya atau adat istiadat. Hal ini bertujuan agar masyarakat setempat tidak sembarangan dalam penggunaan potensi yang ada secara ilegal yang menyebabkan timbulnya berbagai masalah alam lainnya.

Dengan berbagai upaya dilakukan untuk melestarikan hutan, tidak lepas pula dengan keterkaitan kearifan lokal, yang mana mampu membantu dalam pelestarian lingkungan hutan sendiri. Beberapa daerah seperti di Lamandau dan Bangka menerapkan konservasi dengan mengkaitkan kearifan lokal masyarakat daerah dalam melakukan pelestarian serta pengelolaan hutan ini (Hujjatusnaini, 2016). Hal ini juga sangat penting tentunya bagi pengembangan kawasan konservasi yang mana perlu memperhatikan kondisi sosial budaya daerah setempat.

Betapa pentingnya menjaga kelestarian ekosistem yang ada di dunia ini. Untuk itu, kita sebagai manusia tentunya perlu melestarikan keberagaman yang ada ini. Dengan demikian, peran masyarakat dan juga pemerintah sangat penting dalam konservasi kawasan hutan untuk memajukan taraf hutan yang lebih baik kedepannya. Pada studi literature review ini akan membahas terkait peran dan keikutsertaan masyarakat untuk melestarikan hutan serta kebudayaan atau adat istiadat masyarakat dalam konservasi hutan. Adapun sasaran untuk mencapai tujuan adalah menganalisis dan mengidentifikasi variabel serta parameter dari peran masyarakat terhadap konservasi hutan serta adat istiadat dalam melakukan konservasi hutan tersebut.

\section{METODOLOGI PENELITIAN}

Penelitian ini menggunakan metode penelitian kajian pustaka (literature review) dengan cara mengumpulkan data-data dari berbagai sumber berupa buku, jurnal, maupun sumber-sumber lainnya yang relevan. Metode ini digunakan untuk menemukan, menganalisis, mengklasifikasi, dan menyimpulkan dari sumber-sumber ilmiah untuk menemukan hasil dari indentifikasi kami.

Tahapan pengumpulan data dalam penelitian ini yaitu: 
1) Menentukan tema penelitian yang akan dianalisis

2) Mencari artikel ataupun jurnal yang dapat digunakan untuk mendukung penelitian.

3) Menganalisis artikel maupun jurnal yang telah didapatkan.

4) Mengklasifikasi variabel dan parameter yang ada dalam penelitian.

5) Menulis serta menyimpulkan hasil penelitian menjadi artikel penelitian 
Berdasarkan latar belakang tersebut berikut merupakan variabel, indikator, dan parameter dari "Peran Masyarakat Terhadap Konservasi Hutan".

Tabel Variabel, Indikator dan Parameter

\begin{tabular}{|c|c|c|c|c|c|}
\hline No. & Sumber & Uraian & Variable & Indikator & Parameter \\
\hline 1. & $\begin{array}{l}\text { Rani, Zakiyah, \& } \\
\text { Benardi, } 2019\end{array}$ & $\begin{array}{l}\text { Pentingnya konservasi hutan } \\
\text { evergreen untuk menjaga } \\
\text { kelestarian tumbuhan, hewan } \\
\text { dan untuk menunjang kebutuhan } \\
\text { oksigen bagi manusia maka } \\
\text { diperlukan suatu upaya untuk } \\
\text { menjaga kawasan hutan } \\
\text { evergreen }\end{array}$ & \multirow[t]{2}{*}{$\begin{array}{l}\text { Pengelolaan } \\
\text { Konservasi } \\
\text { Hutan }\end{array}$} & $\begin{array}{l}\text { Pelestarian } \\
\text { hutan }\end{array}$ & $\begin{array}{l}\text { Diadakannya reboisasi yaitu } \\
\text { menanam kembali pohon yang } \\
\text { sudah rusak, dengan adanya } \\
\text { sistem reboisasi ini hutan akan } \\
\text { semakin terjaga kelestariaannya. } \\
\text { Melakukan penebangan } \\
\text { konserfatif yaitu memilih pohon } \\
\text { yang sudah tua dan } \\
\text { menggantinya dengan pohon } \\
\text { baru yang dapat menghasilkan } \\
\text { oksigen lebih banyak. } \\
\text { Mengidentidikasi dan mencegah } \\
\text { terjadinya kebakaran hutan. }\end{array}$ \\
\hline 2. & $\begin{array}{l}\text { Henri, Hakim, \& } \\
\text { Batoro, } 2018\end{array}$ & $\begin{array}{l}\text { Upaya masyarakat yang } \\
\text { memanfaatkan sumber daya } \\
\text { alam secara bertahap dan tidak } \\
\text { merusaknya adalah salah satu } \\
\text { pengelolaan kawasan konservasi } \\
\text { hutan yang terus dikembangkan, } \\
\text { pemanfaatan hutan bagi } \\
\text { masyarakat adalah untuk } \\
\text { membudidayakan sesuatu yang } \\
\text { dapat bernilai. }\end{array}$ & & $\begin{array}{l}\text { Pemanfaatan } \\
\text { hutan }\end{array}$ & $\begin{array}{l}\text { Menjadikan kawasan lindung } \\
\text { dan kawasan budidaya } \\
\text { diperuntukan supaya dapat } \\
\text { menjaga keseimbangan } \\
\text { ekosistem, mengendalikan erosi } \\
\text { dan memelihara kesuburan tanah }\end{array}$ \\
\hline 3. & Rani et al., 2019 & $\begin{array}{l}\text { Melibatkan wistawan secara } \\
\text { langsung untuk menjaga } \\
\text { kelestarian hutan dengan } \\
\text { mengikuti program penanaman }\end{array}$ & $\begin{array}{l}\text { Masyarakat } \\
\text { Lokal }\end{array}$ & $\begin{array}{l}\text { Pelestarian } \\
\text { hutan }\end{array}$ & $\begin{array}{l}\text { Adanya program yang } \\
\text { melibatkan masyarakat agar } \\
\text { berperan aktif terhadap kawasan } \\
\text { hutan agar dpat menjaga sumber } \\
\text { daya alam dengan baik. }\end{array}$ \\
\hline
\end{tabular}




\begin{tabular}{|c|c|c|c|c|c|}
\hline No. & Sumber & Uraian & Variable & Indikator & Parameter \\
\hline & & $\begin{array}{l}\text { pohon atau aksi bersih } \\
\text { lingkungan bagi wisatawan yang } \\
\text { mengunjungi tempat konservasi } \\
\text { hutan. }\end{array}$ & & & \\
\hline 4. & $\begin{array}{l}\text { Nabilla et al., } \\
2017\end{array}$ & $\begin{array}{l}\text { Pengembangan hutan rakyat } \\
\text { diarahkan kepada usaha-usaha } \\
\text { rehabilitasi dan konservasi lahan } \\
\text { di luar kawasan hutan negara, } \\
\text { penganekaragaman hasil } \\
\text { pertanian yang diperlukan oleh } \\
\text { masyarakat, peningkatan } \\
\text { pendapatan masyarakat, } \\
\text { penyediaan kayu sebagai bahan } \\
\text { baku bangunan, bahan baku } \\
\text { industri, penyediaan kayu bakar, } \\
\text { usaha perbaikan tata air dan } \\
\text { lingkungan, serta sebagai } \\
\text { kawasan penyangga bagi } \\
\text { kawasan hutan negara. }\end{array}$ & & $\begin{array}{l}\text { Pemanfaatan } \\
\text { hutan sebagai } \\
\text { ekonomi }\end{array}$ & $\begin{array}{l}\text { Menjadikan kawasan hutan } \\
\text { produksi dimana sebagai pemilik } \\
\text { atau pengelola hutan yang baik, } \\
\text { manusia harus mampu } \\
\text { membedakan mana pohon yang } \\
\text { sudah layak untuk ditebang dan } \\
\text { yang belum layak untuk } \\
\text { ditebang. } \\
\text { Menjadikan tempat wisata alam } \\
\text { yang ramah lingkungan dan } \\
\text { dapat dikelola langsung oleh } \\
\text { masyarakat sekitar. }\end{array}$ \\
\hline 5. & $\begin{array}{l}\text { Daroini, Rahayu, } \\
\& \text { Talkah, } 2020\end{array}$ & $\begin{array}{l}\text { Aktifitas pariwisata di Indonesia } \\
\text { sudah mulai tumbuh dan } \\
\text { berkembang, sehingga } \\
\text { diharapkan dapat menjadi sektor } \\
\text { unggulan yang mampu } \\
\text { menggerakkan ekonomi } \\
\text { masyarakat }\end{array}$ & & & $\begin{array}{l}\text { Menjadikan kawasan hutan } \\
\text { sebagai area konservasi tanaman } \\
\text { obat yang dilengkapi dengan } \\
\text { fasilitas wisata edukasi hutan } \\
\text { obat } \\
\text { - } \quad \text { Sebagai upaya untuk } \\
\text { melestarikan wisata hutan obat. }\end{array}$ \\
\hline
\end{tabular}




\section{HASIL DAN PEMBAHASAN}

Pada hasil dan pembahasan ini akan menjelaskan adanya peran masyarakat serta kebudayaan dalam berbagai wilayah Indonesia yang memiliki pengaruh terhadap konservasi hutan. Perlu kita ketahui bahwa adanya hutan adalah sebagai keseimbangan sumber daya alam untuk hewan maupun tumbuhan hidup. Adanya peran aktif masyarakat terhadap konservasi hutan ini dapat membantu alam dan lingkungan hidup agar tidak rusak dimasa yang akan datang.

\section{A. Peran Masyarakat Terhadap Konservasi hutan}

Hutan sebagai sumber daya alam yang merupakan karunia dari Tuhan yang harus kita syukuri dan menjaga kelestariannya. Hutan di Indonesia keberadaannya memiliki berbagai manfaat bagi kehidupan baik digunakan secara langsung maupun tidak langsung. Manfaat untuk secara langsung adalah kebutuhan pangan dan kebutuhan papan yang dapat digunakan sebagai perabotan rumah tangga. Untuk manfaat secara tidak langsung adalah sebagai devisa negara, membantu menjaga keseimbangan air dan tanah serta dapat bermanfaat bagi sektor pariwisata (Nabilla et al., 2017).

Partisipasi masyarakat dalam konservasi hutan sangatlah penting, oleh karena itu pada setiap kawasan lindung di Indonesia tentunya masyarakat terlibat dalam pelestariannya. Adapun peran masyarakat yang telah dilakukan dalam berbagai bentuk seperti dengan kegiatan yang berkaitan dengan gerakan pecinta alam yang mengkaitkan kearifan lokal atau kepercayaan masyarakat setempat. Seperti yang dilakukan masyarakat Desa Colo yang memiliki kepercayaan pada tanaman Pakis Haji, Piring Towo, Pohon Mranti dan Prajito yang mana dipercayai memiliki khasiat yang mujarab. Selain itu, masyarakat Desa Colo juga memiliki kebudayaan terkait upacara atau tradisi seperti sedekah bumi dimaha hal ini dilakukan sebagai sarana komunikasi manusia dengan alam sekitar (Saputri, 2020).

Selain itu, partisipasi masyarakat di Indralaya Provinsi Sumatera Selatan yang telah dilakukan yaitu dengan melakukan penanaman pohon di hutan gundul, tidak membuka lahan dengan dibakar. Tidak hanya itu, masyarakat setempat juga melakukan berbagai upaya seperti membentuk kelompok cegah bakar yang berguna untuk mencegah pembakaran hutan serta sampah yang dilakukan oleh oknum yang tidak bertanggung jawab. selain itu, madyarakan Indralaya juga membentuk kelompok peduli api guna memelihara hutan dengan menanam 
kembali pohon di hutan yang gundul serta tidak melakukan penebangan pohon secara liar (Perkasa, 2020).

Adapula peran masyarakat di Lamandau yang menggunakan kepercayaan adat istiadat yang mereka percayai akan menjaga dan melindungi kelestarian alam. Adanya adat istiadat yang turun temurun sumber daya alam dapat terus tumbuh dan berkembang, karena telah lama memaknainya dalam bentuk kearifan lokal. Dengan kata lain, sumber daya alam hayati dan nabati perlu dilestarikan dalam suatu periode tertentu untuk memulihkan pertumbuhan dan perkembangan demi tercapainya hasil yang terbaik. Dengan demikian sekiranya dapat mengingatkan pemerintah agar tidak mudah dan mengeluarkan izin kepada para pengembang dan pengusaha untuk pembukaan lahan bagi industri ataupun eksploitasilain yang sifatnya dapat menyebabkan kerusakan lingkungan dan sumber daya alam.

Peran serta kearifan lokal dari masyarakat-masyarakat telah menghasilkan berbagai macam konsep dalam menjaga kelestarian hutan yang ada. Kebudayaan seperti itulah yang akan membuat masyarakat takut akan merusak hutan.

\section{B. Kebudayaan Masyarakat dalam Pelestarian Hutan}

Dalam usaha penanganan konservasi hutan memiliki berbagai bentuk dari partisipasi masyarakatnya yang dapat dilihat dari berbagai aspek seperti dilihat dari mata pencaharian yang berkaitan langsung dengan hutan.

Dari data yang ditemukan, terdapat berbagai pekerjaan yang berkaitan dengan hutan seperti pesanggrem, pembuat arang, pengrajin kursi akar, buruh pencari tunggak dimana pekerjaan ini tentunya memerlukan sumber daya alam dari hutan seperti kayu pohon sebagai bahan utama mereka. Sebagai contoh yang terjadi di Ngeblur dimana mata pencaharian mereka berhubungan dengan kawasan hutan, sehingga dapat menjadi salah satu alasan mereka untuk berpartisipasi dalam penanganan konservasi hutan.

Tak hanya itu, partisipasi yang dilakukan oleh masyarakat di Kalimantan yaitu dengan adanya kepercayaan mereka terhadap roh-roh. Kepercayaan inilah yang membuat mereka takut untuk melakukan perbuatan jahat yang dapat merusak ekosistem yang ada di hutan. Kepercayaan masyarakat di Lamandau yang menjaga kelestarian hutan dengan adat istiadat mereka seperi Tajahan, Kaleka, Sepah-pahewan, dan Pukung Himba. Jika resapi secara mendalam, betapa masyarakat Suku Dayak telah memberikan pelajaran tentang pentingnya 
perlindungan flora dan fauna di lingkungan demi menjaga keseimbangan dan pelestarian alam.

Bangka juga menerapkan konservasi dengan mengkaitkan kearifan lokal masyarakat daerah dalam melakukan pelestarian serta pengelolaan hutan ini. Hal ini juga sangat penting tentunya bagi pengembangan kawasan konservasi yang mana perlu memperhatikan kondisi sosial budaya daerah setempat.

Selain itu, pelestarian dengan kearifan lokal ini berguna untuk mempertahankan adat istiadat yang telah dilestarikan sejak dulu dan tentunya sangat erat kaitaanya dengan masyarakat daerah setempat.

Di Bangka sendiri, terdapat berbagai macam cara untuk melestarikan keindahan alamnya. Seperti, mengkaitkan dengan sejarah dari Hutan Pelawan itu sendiri yang mana dikatakan bahwa hutan ini dikenal dengan sebutan Hutan Kalung oleh masyarakat setempat. Kemudian ada juga dengan mengkaitkan kearifan lokal kegiatan masyarakat seperti kegiatan memanen madu yang disebut dengan Musung Madu, dan tentunya hal ini tidak sedikitpun mengubah fungsi ekosistem yang terdapat di dalamnya.

Selain terdapat tradisi Musung Madu, Bangka juga mempercayai tentang mitos Tumbuh Jamur Pelawan, yang manaa jamur ini memiliki nilai jual yang tinggi. Ada juga dengan cara integrasi konservasi secara berkelanjutan, hal ini bertujuan untuk mengurangi kerusakan alam yang terjadi (Henri et al., 2018).

Secara umum, usaha partisipasi masyarakat dalam usaha konservasi hutan akan mengalami berbagai macam kendala. Hal ini terjadi jika faktor yang menghambat seperti pada tingkat pendidikan yang berkaitan dengan pengetahuan masyarakat terhadap konservasi yang rendah, ketersediaan infrastruktur yang kurang memadai, seta penghasilan masyaraka yang rendah. Hal ini tentunya menjadi alasan masyarakat untuk beralih mengunakan sumber daya yang ada di hutan sebagai penghasilan. Seperti pembuatan berbagai macam perlengkapan rumah yang diolah di meubel, usaha ukir kayu dan lainnya yang berdampak terhadap ekosistem yang ada di hutan. Dikarenakan unsur penunjang ekonomi yang sebagian besar bersumber dari pemanfaatan sumber daya alam, sehingga masyarakat memiliki hak penuh untuk berpartisipasi dalam konservasi guna menjaga kelestarian hutan yang ada. Bagi pemerintah hendaknya memberikan sanksi terhadap oknum yang telah melakukan perbuatan yang tidak bertanggung jawab. Hal ini guna untuk mencegah adanya pemanfaatan secara liar 
terhadap hutan, dan sebagai efek jera terhadap oknum yang melakukan penebangan pohon secara liar.

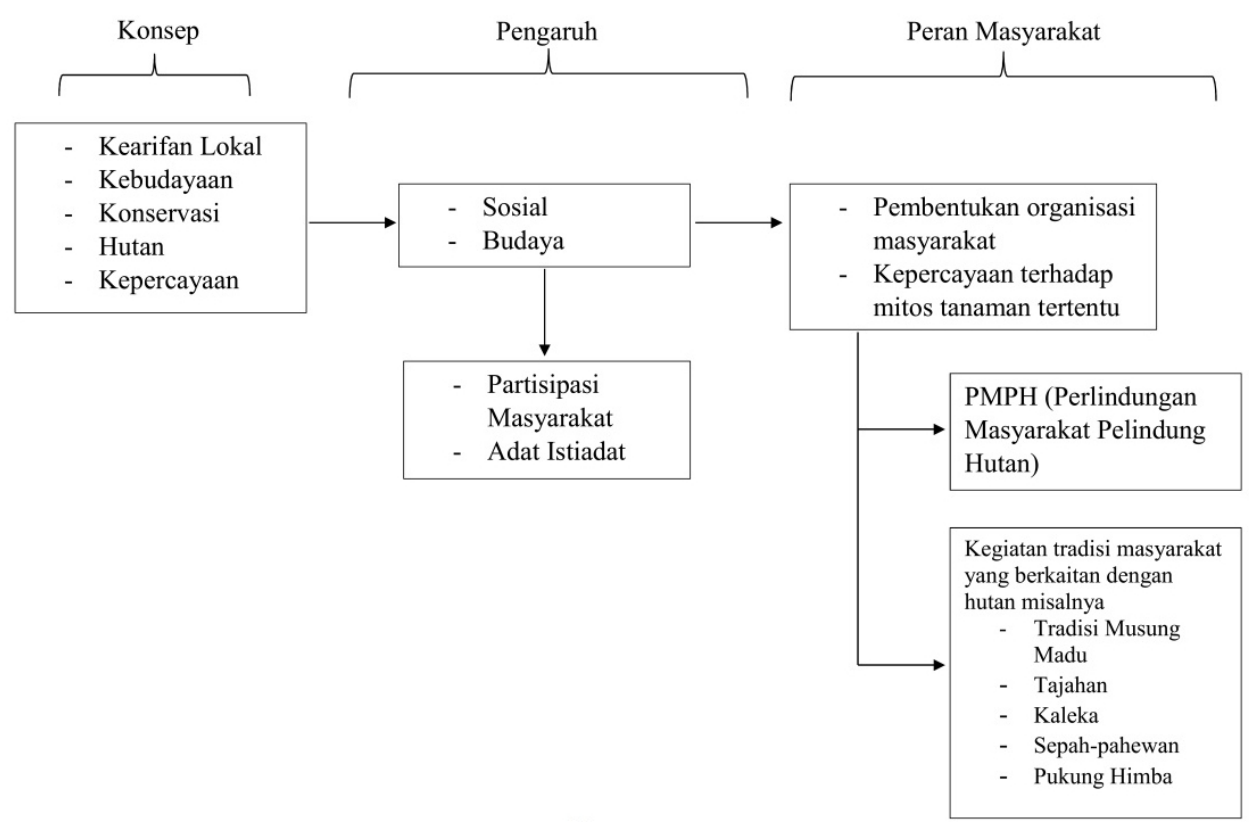

Gambar 1. Analisis Peran Masyarakat Terhadap Konservasi Hutan

\section{KESIMPULAN DAN REKOMENDASI}

\section{A. KESIMPULAN}

Peran masyarakat terhadap konservasi hutan adalah salah satu bentuk dalam melestarikan dan mengelola hutan agar terjaga keseimbangan ekosistem lingkungan serta memberikan penyadaran akan pentingnya menjaga lingkungan dan hutan untuk memajukan taraf hutan yang lebih baik kedepannya dan supaya kedepannya hutan Indonesia bisa tetap menjadi penyumbang oksigen kepada seluruh dunia. Berdasarkan penelitian mengenai analisis yang telah dilakukan berdasarkan artikel serta jurnal yang telah didapatkan tersebut dapat disimpulkan ke dalam beberapa hal:

1. Upaya pelestarian kawasan hutan sebagai kawasan konservasi yang dilindungi dan dilestarikan oleh masyarakat maupun pemerintah. Dalam hal ini perlu adanya sosialisasi kepada masyarakat betapa pentingnya menjaga kelestarian hutan agar masyarakat tidak menyalahgunakan hutan secara sembarangan, serta pemerintah yang membuat peraturan tentang konservasi hutan dan memberikan kesempatan kepada masyarakat untuk 
berinisiatif dan berperan aktif, hal ini memungkinkan adanya interaksi positif yang dapat menumbuhkan rasa ikut memiliki dan menjaga kawasan konservasi hutan.

2. Adanya unsur kebudayaan masyarakat dalam melestarikan hutan serta menjaga hutan agar sumberdaya yang ada didalamnya dapat terjaga keberadannya. Unsur kebudayaan masyarakat ini tidak lepas dari adat istiadat yang telah turun temurun ada pada suatu daerah tersebut seperti tradisi Musung Madi di Bangka yang memanen madu dengan cara tradisional yang tidak merusak ekosistem yang ada di hutan. Dan seperti di daerah Kalimantan yang percaya bahwa adanya roh-roh hutan yang membuat mereka takut untuk merusak hutan serta ekosistemnya.

\section{B. REKOMENDASI}

Analisis mengenai peran masyarakat terhadap konservasi hutan telah diuraikan di atas, berikut ini adalah rekomendasi untuk beberapa pihak terutama yang berkaitan dengan mengelola dan melestarikan hutan, adalah sebagai berikut:

1. Menciptakan program penyelenggaraan konservasi hutan. Hal ini ditandai dengan adanya unsur kebudayaan suatu daerah terhadap menjaga kelestarian.

2. Peran pemerintah perlu ditingkatkan untuk dapat mendukung dan mengembangkan potensi masyarakat dalam mengelola hutan yang dimiliki daerah agar kualitas hutan dapat terjadi terjaga.

3. Kerjasama antara masyarakat dan pemerintah perlu dilakukan secara lebih intensif baik secara langsung maupun tidak langsung.

4. Pemerintah hendaknya mengeluarkan peraturan peraturan terhadap penggunaan atau pemanfaatan sumber daya alam. Hal ini berguna untuk menanggulangi adanya penyalahgunaan sumber daya alam yang tidak benar oleh pihak yang tidak bertanggung jawab. 


\section{DAFTAR PUSTAKA}

Amalya R.O. (2019). Intip Hutan: Good Forest Govermance Need Good Forets Information "Permasalahan Dalam Hutan Kita". February 21, 2020. http://fwi.or.id/publikasi/intiphutan-2019-1/

Daroini, A., Rahayu, R. S., \& Talkah, A. (2020). Strategi Pengembangan Wisata Edukasi Hutan Obat Mbambingan Gunung Kelud Kabupaten Kediri. 4, 400-410.

Henri, Hakim, L., \& Batoro, J. (2018). Kearifan Lokal Masyarakat sebagai Upaya Konservasi Hutan. 16(1), 49-57. https://doi.org/10.14710/jil.16.1.49-57

Herdiansyah, I. (2017). Studi Kasus Strategi Pemberdayaan Masyarakat Hutan Sokokembang LSM swaraOwa di Kabupaten Pekalongan. (14010115120033).

Hujjatusnaini, N. (2016). Konservasi Hutan Di Lamandau dengan Konsep Bioremiadiasi dan Adat Dayak Kaharingan. 4, 498-510.

Liando, D. M., Pratiknjo, M., \& Tunas, M. M. (2017). Partisipasi Masyarakat Dalam Pengembangan Ekowisata Taman Hutan Raya Gunung Tumpang H.V.W Orang Provinsi Sulawesi Utara. 28-39.

Mandiriati, H., Marsono, D., Poedjirahajoe, E., \& Sadono, R. (2016). Konservasi Keanekaragaman Jenis Tumbuhan Jawa di Kebub Raya Baturraden di Kawasan Bekas Hutan Produksi Terbatas. Jurnal Lingkungan Hidup, 14(1), 33-38. https://doi.org/10.14710/jil.14.1.33-38

Nabilla, S., Mulyono, M., Sudaryatmi, S., Studi, P., Ilmu, S., Hukum, F., ... Banten, P. (2017). Implikasi Putas Mk Terhadap Eksistensi Hutan Adat Masyarakat Yang Tumpang Tindih Dengan Hutan Konservasi Taman Nasional Gunung Halimun Salak. 6(35), 1-22.

P, E. I. K., Gerihano, \& Simanjuntak, S. M. H. (2016). Strategi Pengelolaan Kawasan Hutan Taman Nasional Kerinci Seblat ( TNKS ) Provinsi Jambi. 120, 120-125.

Perkasa, D. G. (2020). Community Participation In Management Of Post Asap Farming Forests In Indralaya District, South Sumatera Province.

Praditya, R. (2016). Penyelesaian Konflik Tenurial Kehutanan. (November), 256-260.

Prasetio, R. T., \& Ripandi, E. (2019). Optimasi Klasifikasi Jenis Hutan Menggunakan Deep Learning Berbasis Optimize Selection. Jurnal Informatika, 6(1), 100-106. https://doi.org/10.31311/ji.v6i1.5176

Putra, M. S. W., Zainal, S., \& Idham, M. (2018). Persepsi Dan Partisipasi Masyarakat Dalam Pelestarian Hutan Rumah Pelangi Sebagai Kawasan Konservasi. Jurnal Tengkawang, $8(1), 26-37$.

Rafi, M., Novarino, W., Rizaldi, \& Ardiyanto, A. (2017). Aktivitas Kuau Raja (Argusianus Argus Linnaeus, 1766) Pada Mating Ring Di Hutan Konservasi Kalaweit Supayang, Solok, Sumatera Barat Activity. Jurnal Metamorfosa, 64(1), 58-64.

Rani, S., Zakiyah, N., \& Benardi, A. I. (2019). Edu Geography Motif Awan ( Model Partisipatif Wisatawan ) Sebagai Solusi Konservasi Hutan Evergreen di Taman Nasional Bali Barat. 7(2), 188-197.

Rosmaladewi, O., Danuwikarsa, I., \& Panggabean, M. (2019). Pengelolaan Hutan Bersama Multistakeholder melalui Pengembangan Agroforestry Kopi Organik di Kawasan Hutan Darajat Kabupaten Garut. 2, 641-646.

Rosmaladewi, O., Irmawatie, L., Adviany, I., \& Mustariani, E. (2016). Rehabilitasi \& Konservasi Lingkungan Berbasis Masyarakat "Darling Menjadikan Kawasan Hutan 
Lestari Dan Siaga Bencana”. Jurnal Pengabdian Kepada Masyarakat, 6(1), 1-10.

Saputri, W. E. (2020). Pelestarian Lingkungan Hidup Berdasarkan Kearifan Lokal Masyarakat Colo Wahyu. (April), 1-7.

Suci, Dahlan, Z., \& Yustian, I. (2017). Propil Vegetasi di Kawasan Hutan Konservasi Suaka Margasatwa Gunung Raya Kecamatan Warkuk Kabupaten Oku Selatan. Jurnal Penelitian Sains, 19(1), 47-53.

Suliantoro, B. W., Woro, C., Runggandini, M., Ekonomi, F., Atma, U., Yogyakarta, J., ... Yogyakarta, J. (2018). Model Penyelesaian Konflik Pemanfaatan Sumber Daya Hutan Berperspektif Gender Berbasis Kearifan Lokal Model Of Completion Conflict Use Of Forest Resources. 19(1), 63-74.

Surati, \& Sylviani. (2016). Peran Para Pihak Dalam Penanganan Konflik Di Kesatuan Pengelolaan Hutan Produksi Delta Mahakam, Kalimantan Timur. Jurnal Analisis Kebijakan, 13(3), 221-235.

Utami, S., \& Baskoro, K. (2017). Konservasi Ekosistem Hutan Melalui Kajian Keanekaragaman Jenis Pohon Di Hutan Wisata Nglimut Gonoharjo, Kendal Jawa Tengah. Jurnal Penelitian, 27-33.

Widjanarko, M. (2016). Modal Sosial Masyarakat Desa Rahtawu : Studi Kasus Pelestarian Hutan Muria The Social Capital Of Rahtawu Community: A Case Study Of Forest Conservation. 18(1), 109-120.

Widodo, S. (2019). Membangun Pendidikan Antikorupsi di Sekolah Dasar. Jurnal Pendidikan Dasar, 10(1), 35-44. https://doi.org/doi.org/10.21009/10.21009/JPD.081

Wikipedia Hutan. February 21, 2020. https://id.wikipedia.org/wiki/Hutan

Zainal, L. M., A.Tjoneng, \& S.Numba. (2019). Strategi Pengelolaan Hutan Rakyat Di Kabupaten Sinjai (People's Forest Management Strategy in Sinjai District). 3(1), 11-23. 